\title{
Prevalence and characterisation of non-cholerae Vibrio spp. in final effluents of wastewater treatment facilities in two districts of the Eastern Cape Province of South Africa: implications for public health
}

\author{
Anthony I. Okoh • Timothy Sibanda • \\ Vuyokazi Nongogo • Martins Adefisoye • \\ Osuolale O. Olayemi $\cdot$ Nolonwabo Nontongana
}

Received: 2 July 2014 / Accepted: 14 August 2014 / Published online: 29 August 2014

(C) The Author(s) 2014. This article is published with open access at Springerlink.com

\begin{abstract}
Vibrios and other enteric pathogens can be found in wastewater effluents of a healthy population. We assessed the prevalence of three non-cholerae vibrios in wastewater effluents of 14 wastewater treatment plants (WWTP) in Chris Hani and Amathole district municipalities in the Eastern Cape Province of South Africa for a period of 12 months. With the exception of WWTP10 where presumptive vibrios were not detected in summer and spring, presumptive vibrios were detected in all seasons in other WWTP effluents. When a sample of 1,000 presumptive Vibrio isolates taken from across all sampling sites were subjected to molecular confirmation for Vibrio, 668 were confirmed to belong to the genus Vibrio, giving a prevalence rate of $66.8 \%$. Further, molecular characterisation of 300 confirmed Vibrio isolates revealed that $11.6 \%$ (35) were Vibrio parahaemolyticus, $28.6 \%$ (86) were Vibrio fluvialis and $28 \%$ (84) were Vibrio vulnificus while $31.8 \%$ (95) belonged to other Vibrio spp. not assayed for in this study. Antibiogram profiling of the three Vibrio species showed that $V$. parahaemolyticus was $\geq 50 \%$ susceptible to 8 of the test antibiotics and $\geq 50 \%$ resistant to only 5 of the 13 test antibiotics, while $V$. vulnificus showed a susceptibility profile of $\geq 50 \%$ to 7 of the test antibiotics and a resistance profile of $\geq 50 \%$ to 6 of the 13 test antibiotics. $V$. fluvialis showed $\geq 50 \%$ resistance to 8 of the 13 antibiotics used while showing $\geq 50 \%$ susceptibility to only 4 antibiotics used. All
\end{abstract}

Responsible editor: Philippe Garrigues

A. I. Okoh $\cdot$ T. Sibanda $(\bowtie) \cdot$ V. Nongogo $\cdot$ M. Adefisoye $\cdot$

O. O. Olayemi $\cdot$ N. Nontongana

Applied and Environmental Microbiology Research Group

(AEMREG), Department of Biochemistry and Microbiology,

University of Fort Hare, P Bag X1314, Alice, Eastern Cape 5700,

South Africa

e-mail: timsibanda@gmail.com three Vibrio species were susceptible to gentamycin, cefuroxime, meropenem and imipenem. Multiple antibiotic resistance patterns were also evident especially against such antibiotics as tetracyclin, polymixin B, penicillin $\mathrm{G}$, sulfamethazole and erythromycin against which all Vibrio species were resistant. These results indicate a significant threat to public health, more so in the Eastern Cape Province of South Africa which is characterised by widespread poverty, with more than a third of the population directly relying on surface water sources for drinking and daily use.

Keywords Vibrio · Public health · Wastewater . Antibiogram · Prevalence

\section{Introduction}

Municipal wastewater, even if treated, may still contain a wide range of pathogens that are excreted by diseased humans (Arceivala 1997; Wen et al. 2009), contributing to increased densities of pathogens in the receiving water bodies. Surface water bodies are major sources of potable water whose unabated contamination has led to many water-related disease outbreaks in the past (Mishra et al. 2004; Nair et al. 2004; Obi et al. 2004). Although wastewater treatment technologies can, with optimised performance, reduce bacterial and viral pathogens by approximately $90 \%$ (Asano and Levine 1998; Jiménez et al. 2004), it is not possible for the microbial quality of the effluents to match the microbial quality of the water in the receiving water bodies. Discharge of effluents will, therefore, despite the level of treatment, potentially alter the microbial content of the receiving water bodies (Drury et al. 2013). 
Previous studies show that some Vibrio species survive the activated sludge-based wastewater treatment process as free cell and as plankton-associated entities (Igbinosa et al. 2009, 2011), suggesting that the provision of wastewater treatment facilities does not, in itself, ensure satisfactory effluent water quality. The most common clinical presentation of Vibrio infection is self-limited gastroenteritis, but wound infections and primary septicaemia may also occur (Levine and Griffin 1993). Healthy carriers of Vibrio cholerae excrete vibrios intermittently, with chronic convalescent carriers shedding vibrios intermittently for periods of 4 to 15 months (Nevondo and Cloete 2001). Survival of vibrios in the aquatic environment relates sharply to various chemical, biological and physical characteristics of the aquatic milieu, with $V$. cholerae known to remain viable in surface waters for periods ranging from 1 h to 13 days, while faecal contamination from victims of epidemics and healthy carriers may continue to reinforce their concentrations in water (Nevondo and Cloete 2001). As a result, cholera and cholera-like infections continue to be a substantial health burden in developing countries, especially in Africa and Asia, compromising the primary health of vulnerable members of society (Bourne and Coetzee 1996; Pegram et al. 1998; Mackintosh and Colvin 2003). Vibrio species have been incriminated in cases of diarrhoea, accounting for a substantial degree of morbidity and mortality in different age groups worldwide (Obi et al. 2004). The most notable of Vibrio pathogens are $V$. cholerae, Vibrio parahaemolyticus, Vibrio vulnificus and Vibrio fluvialis (CDC Centers for Disease Control and Prevention 1999; Finkelstein et al. 2002; Kothary et al. 2003; Chakraborty et al. 2006) which are mainly transmitted via water and food. They all cause diarrhoea, but in entirely different ways; $V$. vulnificus and $V$. parahaemolyticus are invasive organisms, affecting primarily the colon, while $V$. cholerae is non-invasive, affecting the small intestine through secretion of an enterotoxin (Todar 2005), and is the etiologic agent of cholera. The clinical symptoms of $V$. fluvialis gastroenteritis are similar to cholera with the additional manifestation of bloody stools which is suggestive of an invasive pathogen (Oliver and Kaper 2001). Other vibrios like Vibrio alginolyticus, Vibrio cincinnatiensis, Vibrio furnisii, Vibrio harveyi, Vibrio metschnikovii and Vibrio mimicus have occasionally been reported as causes of human infections (Farmer and Hickman-Brenner 1992; Abbott and Janda 1994; Carnahan et al. 1994). However, of all the Vibrio species which have been associated with illness in humans, the most important are $V$. cholerae subgroups $\mathrm{O} 1$ and $\mathrm{O} 139$, the causative agents of epidemic cholera (Heymann 2008). Heidelberg et al. (2002) have reported large numbers of vibrios, about $4.3 \times 10^{6} / \mathrm{mm}^{2}$, attached to the external surface of plankton (zooplankton and phytoplankton), pointing to a close association between vibrios and planktons. This association has also been observed in municipal wastewaters (Ahmadi et al. 2005; Chindah et al.
2007; Mukhopadhyay et al. 2007). V. fluvialis, in particular, has been identified as an important cause of cholera-like bloody diarrhoea and primary septicaemia in immunocompromised individuals, especially in underdeveloped countries with poor sanitation (Igbinosa and Okoh 2010). This organism has been isolated from treated wastewater effluents in South Africa (Igbinosa et al. 2009), and there are reports linking it to food poisoning (Kobayashi and Ohnaka 1989), especially due to consumption of raw shellfish (Levine and Griffin 1993). While adequate and timely rehydration therapy remains the gold-standard treatment for cholera and cholera-like bloody diarrhoea (Heymann 2008), antimicrobials are also prescribed for the management of severe cases in order to shorten the duration of illness and reduce the volume of rehydration solution required. However, some Vibrio strains are resistant to a number of antimicrobials including tetracycline, cotrimoxazole, trimethoprim and sulfamethoxazole. This resistance to antimicrobials, in addition to other properties such as virulence factors and ability to cause epidemics, makes vibrios pathogens of public health concern. Knowledge of the prevalence and antimicrobial resistance profile of local strains is, therefore, important for the management of complicated cases in the case of an epidemic. At times, a cholera outbreak is reported without any clear linkage of the index case to neighbouring countries or travel to affected areas. This usually leaves health authorities asking themselves where the cholera causing bacteria could have come from. We hypothesise that such outbreaks could be related to either persistence of organisms in free-living, altered or adapted forms capable of reverting to a pathogenic variety or to continuous year-round transmission by sub-clinical cases or a combination of both. Routine analysis of the microbial quality of treated wastewater effluents is therefore warranted in order to maintain the microbial load of receiving water bodies within acceptable limits for both human use and lotic ecosystems survival. There is, however, paucity of information on the molecular epidemiology of vibrios in the aquatic milieu of the Eastern Cape Province (ECP) of South Africa. Compounding the challenge is the production of poor-quality effluents by wastewater treatment plants in the ECP which is acknowledged as mostly non-urban, poor and without adequate infrastructure (Mohale 2003; BLACKSASH 2010). Also, the documentation of final effluent compliance of the wastewater treatment plants to set guidelines with respect to bacteriological quality remains poor in the province. This study was, therefore, aimed at assessing the prevalence of non-cholerae vibrios in the final effluents of 14 wastewater treatment facilities in the ECP of South Africa, characterising them into species and determining their antibiogram properties and evaluating the public health implications of the findings. While there are at least 12 pathogenic Vibrio species recognised to cause human illness (Janda et al. 1988), this work was based on the prevalence and characterisation of $V$. vulnificus, $V$. fluvialis and $V$. parahaemolyticus. 
Methodology

\section{Description of study area}

Fourteen (14) wastewater treatment plants (WWTP) were selected in Amathole and Chris Hani district municipalities of the ECP in South Africa (Fig. 1). The choice of WWTP was influenced by the need to ensure that plants were not located more than 3-h drive from the University of Fort Hare in Alice, such that samples could be taken to the laboratory for analysis within $6 \mathrm{~h}$ of collection. The ECP borders the provinces of the Western Cape, Northern Cape, Free State and KwaZulu-Natal, as well as Lesotho in the north. The province is mostly rural with a high percentage of people living in poverty $(67.4 \%)$ and a very low Human Development Index (HDI) of 0.52 (BLACKSASH 2010; ECSECC 2011). It is the second largest province in South Africa and mainly comprised of rural settlements with little or no adequate sanitary facilities, with about $36 \%$ of the population directly reliant on surface water sources for domestic use (ECSECC 2011). The ECP is divided into seven district municipalities, namely, Alfred Nzo, Amathole, Chris Hani, Joe Gqabi, O.R. Tambo, Cacadu and the Nelson Mandela Metropolitan Municipality. The Amathole District Municipality includes the Buffalo City Municipality. Due to the confidential nature of this work, the sampling sites were designated as WWTP1 to WWTP14, and geographical coordinates could equally not be given. All selected WWTPs discharge their treated effluents directly into rivers. Samples were collected with permission from the Amathole and Chris Hani district municipalities.

\section{Sample collection and isolation of presumptive Vibrio organisms}

Wastewater final effluent samples were collected once a month for a period of 12 months starting in August 2012 to July 2013. Samples were collected in sterile 2-1 polypropylene bottles containing $0.1 \%$ of a $3 \%(w / v)$ solution of sodium thiosulphate for sample dechlorination and taken to the Applied and Environmental Microbiology Research Group (AEMREG) laboratory at the University of Fort Hare in Alice, South Africa, in cooler boxes containing ice, for analysis within $6 \mathrm{~h}$ of collection. Samples were serially diluted and concentrated on nitrocellulose membrane filters $(0.45-\mu \mathrm{m}$ pore size, Millipore) by passing $100 \mathrm{ml}$ of each dilution through the filter using the membrane filtration technique as recommended by Standard (2005). The filters were then placed onto agar plates containing thiosulphate citrate bile salts sucrose agar (TCBS agar). For the purposes of quality control, the spread plate technique was also employed where known $(100 \mu \mathrm{l})$ volumes of effluent samples were spread on
TCBS agar as previously described by Igbinosa et al. (2011). Green and yellow colonies were identified and enumerated as presumptive Vibrio isolates. Counts were converted to $\log _{10}$ values and clustered into seasons where spring composed of August 2012-October 2012, summer (November 2012-January 2013), autumn (February 2013, March 2013 and April 2013) and winter (May 2013-July 2013). Presumptive Vibrio colonies were then isolated, purified and subjected to Gram staining and oxidase test. Gram-negative, oxidase positive isolates were selected and preserved in $20 \%$ glycerol at $-80{ }^{\circ} \mathrm{C}$ until further analysis.

\section{Molecular confirmation of Vibrio species}

To extract DNA, single colonies of 18-24 h old presumptive Vibrio cultures grown on nutrient agar plates at $37{ }^{\circ} \mathrm{C}$ were picked, suspended in $200 \mu \mathrm{l}$ of sterile distilled water and the cells lysed using an AccuBlock (Digital dry bath, Labnet) for $15 \mathrm{~min}$ at $100{ }^{\circ} \mathrm{C}$ as described by Maugeri et al. (2006). The cell debris was removed by centrifugation at $11,000 \times g$ for 2 min using a MiniSpin microcentrifuge (Lasec, RSA). Five microlitre $(5 \mu \mathrm{l})$ aliquots of the cell lysates were used as template DNA in polymerase chain reaction (PCR) assays immediately after extraction to determine the molecular identity of the isolates. To confirm if the isolates belonged to the genus Vibrio, the primer set V16S-700F (CGG TGA AAT GCG TAG AGA T) and V16S-1325R (TTA CTA GCG ATT CCG AGT TC) targeting the 16S ribosomal RNA (rRNA) gene (663 bp) was used in PCR assays as described by Kwok et al. (2002).

Vibrio species identification was done using speciesspecific primers targeting specific sequences within the $16 \mathrm{~S}$ rRNA as described by Kim et al. (1999). For V. parahaemolyticus, the primer set Vp. flaE-79F (GCA GCT GAT CAA AAC GTT GAG T) and Vp. flaE-934R (ATT ATC GAT CGT GCC ACT CAC) targeting the $897 \mathrm{bp}$ flaE gene was used as described by Tarr et al. (2007). $V$. vulnificus was identified using the primer set $\mathrm{Vv}$. hsp326F (GTC TTA AAG CGG TTG CTG C) and Vv. hsp697R (CGC TTC AAG TGC TGG TAG AAG) targeting the hsp60 gene (410 bp) as described by Wong and Chow (2002), while the primer set Vf toxR-F (GAC CAG GGC TTT GAG GTG GAC GAC) and Vf toxR-R (AGG ATA CGG CAC TTG AGT AAG ACTC) was used to identify $V$. fluvialis targeting the 217 bp toxR gene as previously described (Osorio and Klose 2000; Chakraborty et al. 2006). In all, 300 confirmed Vibrio isolates were randomly selected from a pool of 668 confirmed Vibrio isolates taken from across all sampling sites and characterised into these three pathotypes using PCR. V. parahaemolyticus DSM 11058, V. fluvialis DSM 19283 and V. vulnificus DSM 11507 were used as positive control strains. 
Fig. 1 A map showing the seven district municipalities of the ECP. Sampling sites were selected in Chris Hani and Amathole district municipalities (http://www. worldlicenseplates.com/world/ AF ZAEC.html)

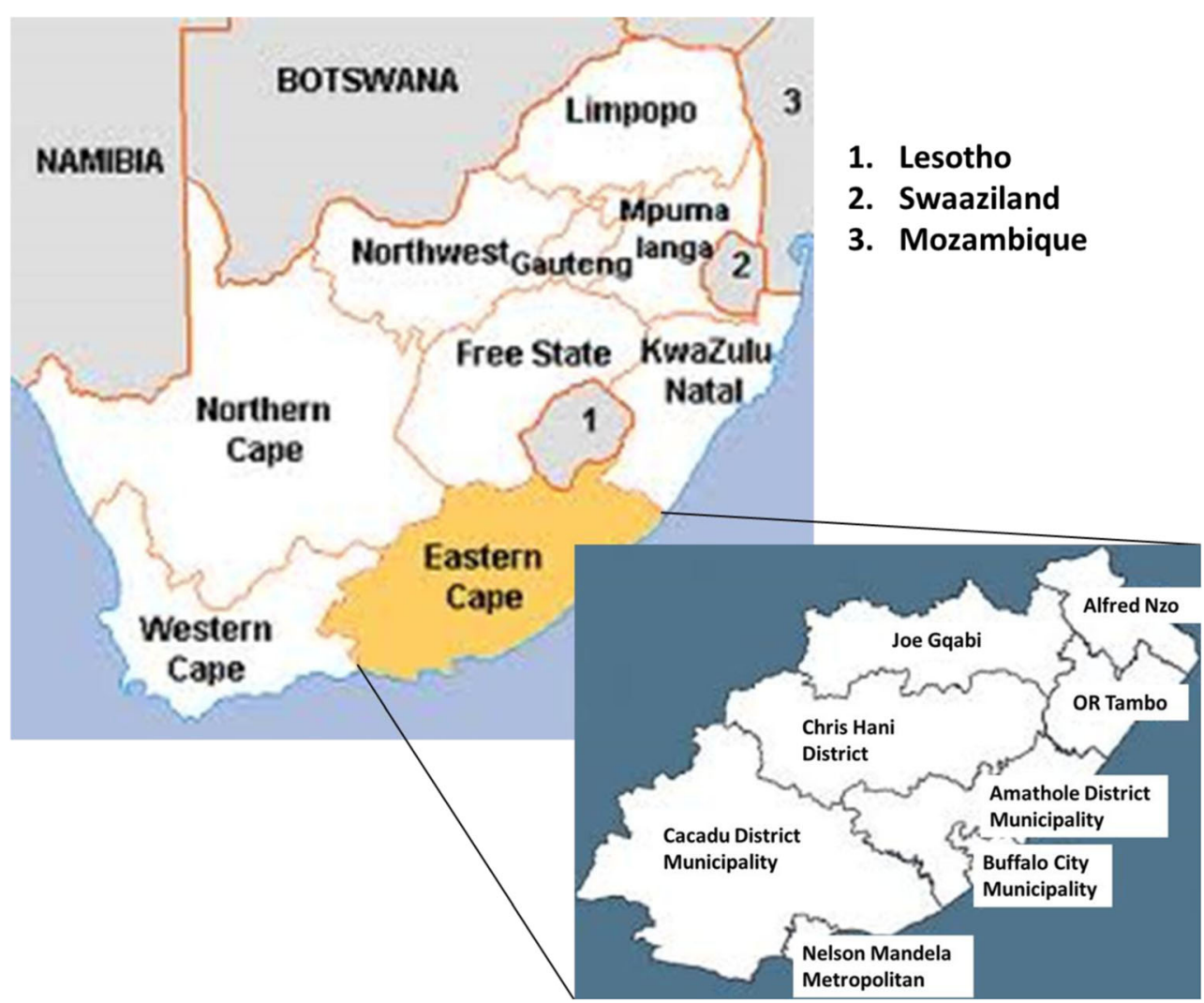

\section{Antibiogram characterisation}

All Vibrio isolates that were positively identified to belong to any of the three pathotypes were subjected to antimicrobial susceptibility testing using the following antibiotics: imipenem, nalidixic acid, erythromycin, sulfamethoxazole, cefuroxime, penicillin $\mathrm{G}$, chloramphenicol, polymixin $\mathrm{B}$, trimethoprim-sulfamethoxazole, tetracycline, gentamicin, meropenem and trimethoprim. Ciprofloxacin and doxycycline have been the antibiotics of choice for adults (except pregnant women) (Steinberg et al. 2001), while erythromycin and trimethoprim-sulfamethoxazole have been recommended for children and pregnant women. These antimicrobial agents are, however, no longer recommended as first-line therapy because of increasing global antimicrobial resistance (Gilbert et al. 1999), and whenever possible, treatment protocols should be based on local antibiogram data (Centers for Disease Control and Prevention 2013).

\section{Statistical analysis}

An independent samples $t$ test (IBM SPSS version 20) was used to compare the mean presumptive Vibrio counts of all the WWTPs and also the mean presumptive Vibrio counts obtained in each of the seasons. Differences were deemed significant at $P<0.05$.

\section{Results and discussion}

Presumptive Vibrio organisms were isolated in all seasons and at all sampling sites with the exception of WWTP10 where presumptive Vibrio was not detected in summer and spring. Gastrointestinal pathogenic microorganisms do not occur as a natural part of the normal intestinal microbiota (Gerritsen et al. 2011). Their presence in wastewater, therefore, could be dependent on the number of infected people in the population contributing to the wastewater flow. The presumptive Vibrio counts for all sampling sites were expressed in $\log _{10}$ values and are presented in Figs. 2 and 3. The error bars on these figures represent the standard deviations since each of the readings is an average of the counts of 3 months constituting each season. Significantly higher presumptive Vibrio counts were obtained in samples from WWTP2 $(P<0.05)$, while samples from WWTP10 had significantly lower counts compared to the rest of the WWTPs. While other studies have reported a reduction in environmental Vibrio densities during winter as compared to other seasons (DePola et al. 2003; de Souza Costa Sobrinho et al. 2010), the trend was different in our case as statistical analysis showed that there was no significant difference in Vibrio densities obtained in different seasons.

South Africa has been plagued by outbreaks of Vibrio-related waterborne infections that are suspected to be linked to 
Fig. 2 Seasonal presumptive Vibrio counts for WWTP1-7

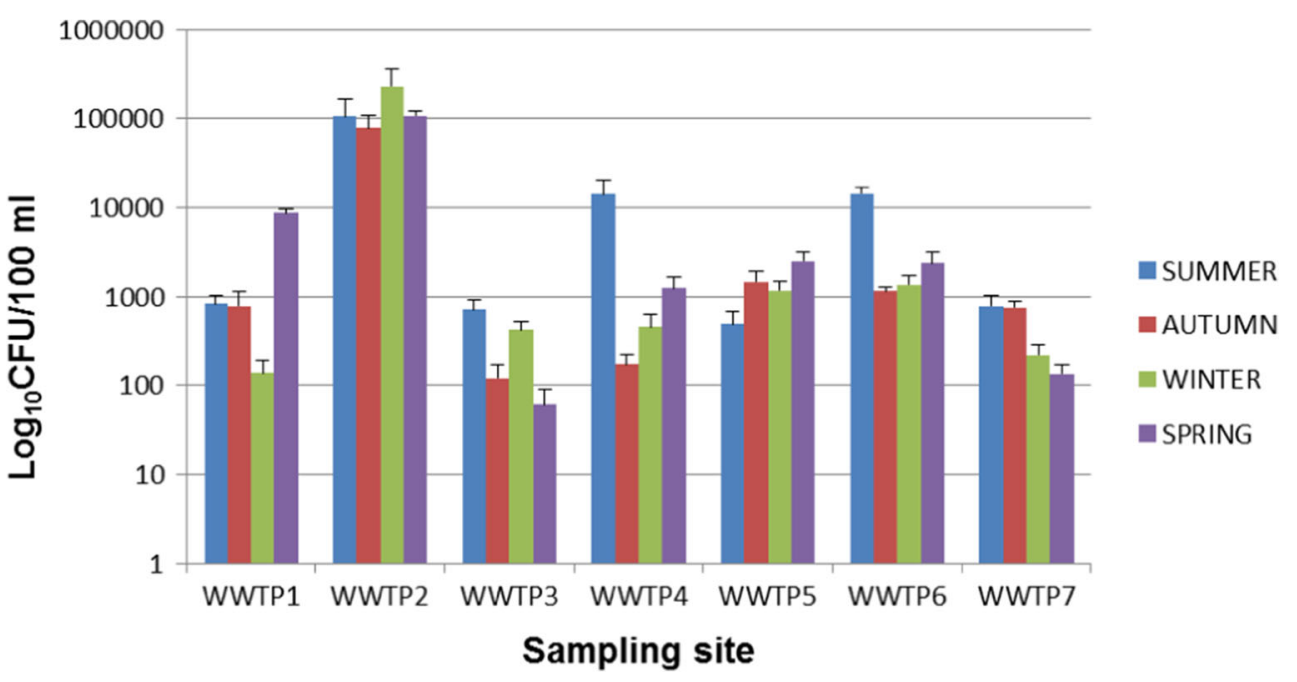

inefficiently treated effluents discharge from wastewater treatment facilities (Igbinosa et al. 2011).

When a randomised sample of 1,000 presumptive Vibrio isolates were subjected to PCR confirmation for Vibrio organisms, 668 isolates tested positive, giving an overall Vibrio prevalence rate of $66.8 \%$. As at the time when this study was carried out, there was no known outbreak of cholera or cholera-like diarrhoea in the ECP and, specifically, in the two districts serviced by the selected 14 WWTPs and yet Vibrio was isolated all the same. Vibrio species are not normal biota for human beings, as some $E$. coli are, neither are they normal biota for fresh water environments, and positive results from this work strongly point to either unreported sporadic incidents of infection within the communities or the existence of healthy Vibrio carriers intermittently shedding vibrios into the environment as suggested by Nevondo and Cloete (2001). Similar findings were obtained by Jackson S. Beney $\mathrm{C}$ (2000) who managed to detect potentially virulent $V$. cholerae in freshwater environments despite the absence of clinical cases in the host population for some time. Harris et al. (2012) also stated that some patients can even be infected with
$V$. cholerae $\mathrm{O} 1$ or $\mathrm{O} 139$ and yet show no symptoms but then tend to shed the organism into the environment, even for only a few days, explaining why vibrios can be isolated in wastewater effluents in a non-Vibrio and/or non-cholera epidemic area. Once these vibrios get into environmental water, they convert to conditionally viable environmental cells within 24 h (Faruque et al. 2005; Nelson et al. 2008). Such vibrios are infectious on reintroduction into a human body, but the infectious dose in this form is not known (Harris et al. 2012). This becomes a major public health time bomb in underdeveloped areas like the ECP where, as of 2011 , about $36 \%$ of the population still got their drinking water directly from rivers and streams (ECSECC 2011). An excerpt from Water Supply, Sanitation and Hygiene (WASH 2010) summed up the challenge as follows,

"Many of South Africa's municipal wastewater treatment plants (WWTP) are not performing to acceptable water quality standards .... A lack of good-quality drinking water leads to health problems, which is serious, given the fact that many poor citizens source water directly from the rivers, where not only municipalities .... Since South Africa does not have large
Fig. 3 Seasonal presumptive Vibrio counts for WWTP8-14

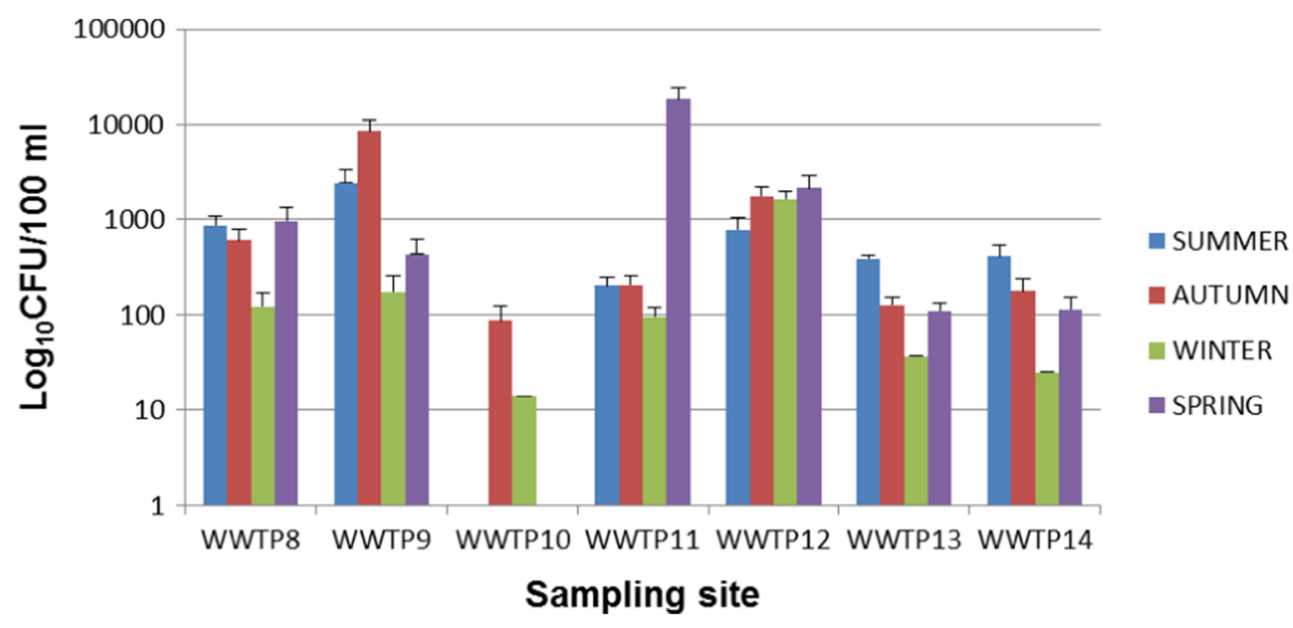


rivers, the discharged effluents concentrate into small watercourses"

If, on the average, every litre of effluent contains about 1,000 presumptive Vibrio organisms, as was the case in this study, and the lowest effluent volume produced by a treatment plant is $0.63 \mathrm{ml} /$ day (WWTP7), there will be a daily addition of about $6.3 \times 10^{8}$ presumptive Vibrio cells into the environment. The resultant health risk to those who drink untreated water directly from the receiving watercourses can be exacerbated if the receiving watercourses are small as this will minimise the dilution capacity and result in concentration of potentially virulent organisms, increasing the risk of illness in the case of raw water ingestion. While there is no available data to show the proportion of effluent in the receiving rivers' annual flow volumes in the ECP or in South Africa in general, the annual flow of the Chicago Area Waterway System (which includes all segments of the Chicago River as well as the North Shore Channel) comprises more than $70 \%$ of treated municipal wastewater effluent (Illinois Department of Natural Resources 2011). While the WWTPs in the ECP may not be as numerous and big as to contribute to as high a percentage of the river flow volume, chances are that they may not be as efficient in pathogen removal, taking into account the excerpt from WASH (2010). Other factors that may increase or upset the risk include the infectious dose of the organisms, the presence or absence of virulent factors in the said vibrios and whether or not people filter their water at home before they drink it. Besides direct consumption of untreated surface water, vibrios concentrate in the gut of filter-feeders such as oysters, clams and mussels, where they multiply (Iwamoto et al. 2010). While thorough cooking will destroy these organisms, oysters are often eaten raw and are the most common food associated with $V$. parahaemolyticus infection in the USA (Hlady 1997). Our findings, though not complemented by assessments for virulence and antibiotic resistance genes, indicate that the potential for disease in the community and call for pro-active rather than reactive measures if public health is to be preserved and unnecessary loss of life avoided.

When 300 of the 668 confirmed Vibrio isolates were further screened into species, $11.6 \%$ (35) were confirmed to be V. parahaemolyticus, $28.6 \%$ (86) were confirmed to be V. fluvialis and $28 \%$ (84) were confirmed to be $V$. vulnificus, while $31.8 \%$ (95) belonged to other Vibrio spp. not assayed for in this study. When these confirmed Vibrio pathotypes were subjected to antibiogram profiling, $V$. fluvialis showed $\geq 50 \%$ resistance to 8 of the 13 antibiotics used while showing $\geq 50 \%$ susceptibility to only 4 antibiotics used (Fig. 4).

Similar results have been reported by Okoh and Igbinosa (2010) whose work showed 100, 92, 90, 70 and $80 \%$ resistances by $V$. fluvialis isolates from rural-based WWTPs to trimethoprim, cephalothin, penicillin, cotrimoxazole and streptomycin, respectively, positioning it as an emerging pathogen in the ECP of South Africa. Antimicrobial resistance has become a major medical and public health problem as it has direct links with disease management and containment. This is reflected by the increase in the fatality rate from 1 to $5.3 \%$ after the emergence of drug resistance strains in GuineaBissau during the cholera epidemic of 1996-1997 (Dalsgaard et al. 2000).

Improved susceptibility to antibiotics was observed in V. parahaemolyticus which showed susceptibilities of $\geq 50$ to $8 \%$ of the test antibiotics and a resistance profile of $\geq 50 \%$ to only 5 of the 13 test antibiotics (Fig. 5).

V. vulnificus showed a susceptibility profile of $\geq 50$ to $7 \%$ of the test antibiotics while showing a resistance profile of $\geq 50$ to $6 \%$ of the 13 antibiotics used (Fig. 6).

All three Vibrio species were susceptible to gentamycin, cefuroxime, meropenem and imipenem. Multiple antibiotic resistance patterns were also evident especially against such antibiotics as tetracycline, polymixin $\mathrm{B}$, penicillin $\mathrm{G}$, sulfamethoxazole and erythromycin against which all Vibrio species were resistant. Similar findings were reported by
Fig. 4 Antimicrobial profile for V. fluvialis $(n=35)$

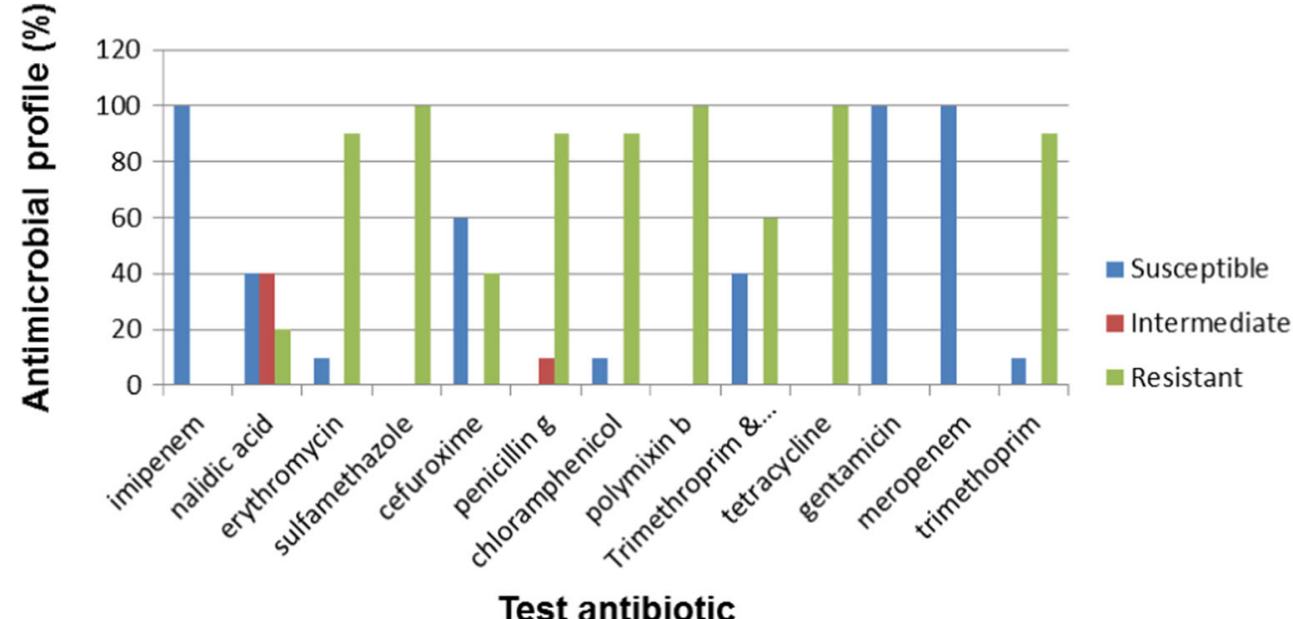


Fig. 5 Antimicrobial profile of V. parahaemolyticus $(n=86)$

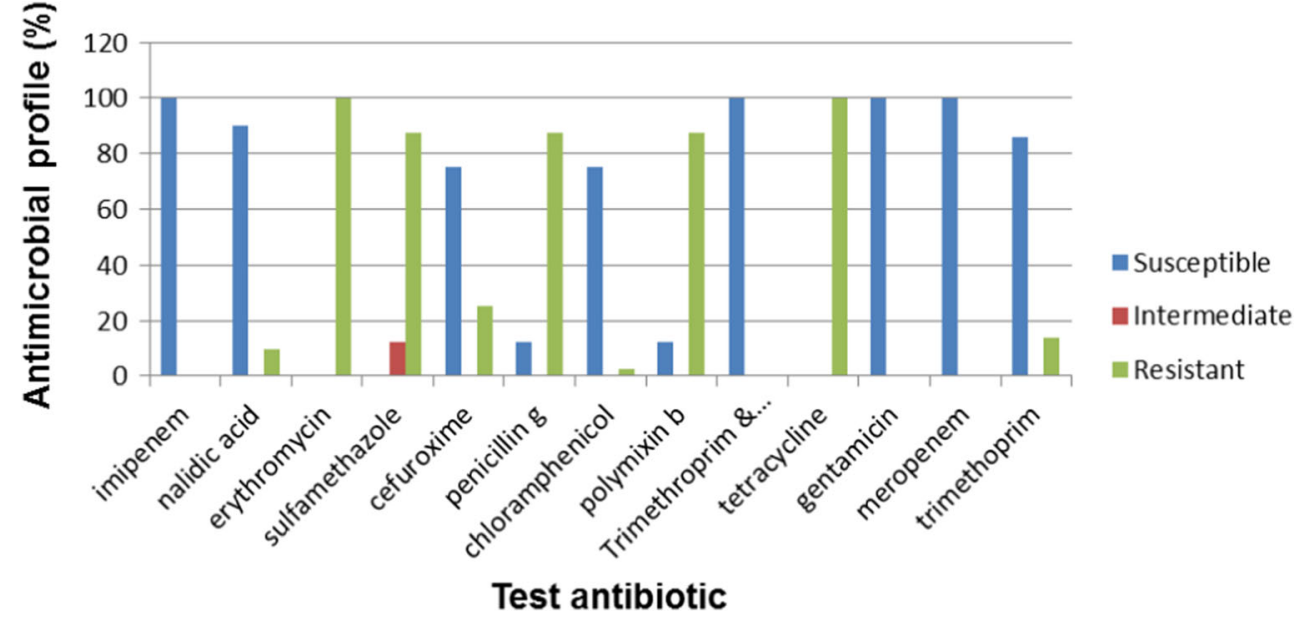

Keddy (2010a) during a cholera outbreak in South Africa in 2009, where the Enteric Diseases Research Unit (EDRU) at the National Institute for Communicable Diseases (NICD) processed $570 \mathrm{~V}$. cholerae $\mathrm{O} 1$ isolates associated with the outbreak. Further laboratory characterisation of the isolates showed that they were $100 \%$ resistant to co-trimoxazole, $48 \%$ resistant to chloramphenicol, $100 \%$ resistant to nalidixic acid, $3 \%$ resistant to tetracycline and $39 \%$ resistant to erythromycin. In another outbreak in 2008, reported from Shebagold Mine in the Ehlanzeni district of Mpumalanga Province in South Africa, 31 isolates were submitted for analysis to the EDRU, revealing that all were biotype El Tor and displayed resistance to ampicillin, amoxycillinclavulanate, sulfamethoxazole, trimethoprim, chloramphenicol, nalidixic acid, kanamycin, streptomycin and tetracycline, which was initially the antimicrobial agent of choice in the treatment of cholera in Africa, although they were susceptible to ciprofloxacin and imipenem (Keddy 2010b; CrowtherGibson et al. 2011).

Our findings prove that wastewater effluents are an important source of antimicrobial resistant bacteria, as reported elsewhere (James et al. 2003; Byarugaba 2004). Atieno et al.
(2013) also stated that the release of pathogenic enteric microorganisms into aquatic environments can be a source of disease when water is used for drinking, recreational activities or irrigation. It has also been noted that the prevalence of pathogenic enteric bacteria in wastewater effluents (and hence in receiving water sources) increases public health risk if the bacteria are antibiotic-resistant because of the reduced efficacy of antibiotic treatment against human diseases caused by such bacteria (Tendencia and De la Pena 2002; Wenzel and Edmond 2009). Baine et al. (1977) reported that a large waterborne outbreak involving $\mathrm{R}+$ bacteria (bacteria with $\mathrm{R}$ factors for antibiotic resistant gene transfer) led to a large number of deaths in Mexico, partly due to the failure of the patients to respond to antibiotics of choice. The New York Times (2013) quoted Centre for Disease Control (CDC) officials as having reported that at least 2 million Americans fall ill from antimicrobial-resistant bacteria every year and that at least 23,000 die from those infections. The paper reported that one particularly lethal type of drug-resistant bacteria, known as carbapenem-resistant Enterobacteriaceae (CRE), has become resistant to nearly all antimicrobials on the US market, further stating that though still relatively rare, CRE causes
Fig. 6 Antimicrobial profile of V. vulnificus $(n=84)$

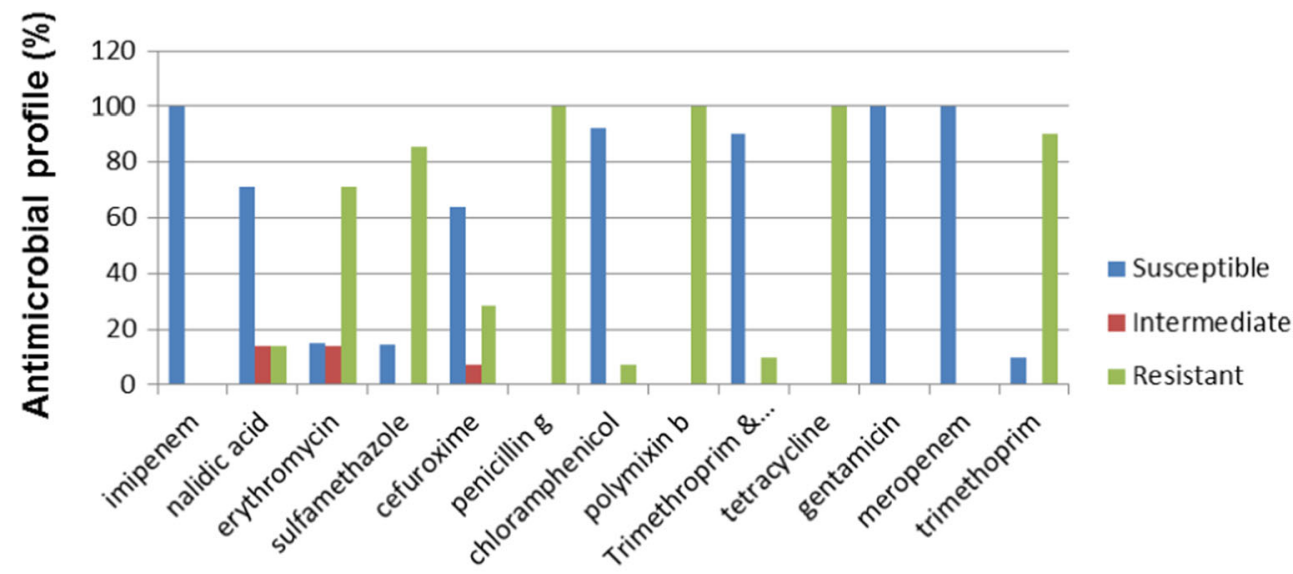

Test antibiotic 
about 600 deaths a year in the US alone. Should the proliferation of antimicrobial resistant organisms be allowed to go unchecked, society will return to a time when people died from ordinary infections. This point is further buttressed by Torrice (Undated), in an article entitled "Multidrug Resistance Gene Released by Chinese WWTP", where he wrote:

\section{In recent years, increasing numbers of patients world- wide have contracted severe bacterial infections that are untreatable by most available antibiotics. Some of the gravest of these infections are caused by bacteria car- rying genes that confer resistance to a broad class of antibiotics called beta-lactams, many of which are treat- ments of last resort. Now a research team reports that some wastewater treatment plants in China discharge one of these potent resistance genes into the environ- ment. Environmental and public health experts worry that this discharge could promote the spread of resistance.}

There is also the possibility of antibiotic resistance genes being transmitted to autochthonous bacteria if such genes are carried by transferable and mobile genetic elements such as plasmids, thus contributing to the spread of antimicrobial resistance (Sayah et al. 2005). Development of drug resistance may be caused by the occurrence of antimicrobial agents at sub-optimal concentrations both in human bodies by continued usage and also in the wastewater matrix via leaching. The correlation between antimicrobial use and antibiotic resistance of commensal bacteria has been documented (Van den Bogaard and Stobberingh 2000). We infer, therefore, that the extent to which bacterial isolates are exposed to antibiotics before their release in the environment could be one of the reasons for the levels of antibiotic resistance shown by Vibrio isolates in this study. A lot has to be done, therefore, to prevent infections with multi-drug resistant organisms which find their way into the environment from WWTPs.

The public is endangered by exposure to wastewater, which happens directly or indirectly. Direct exposure routes include ingestion of contaminated water during recreational activities such as swimming, bathing and when undertaking religious ceremonies like baptisms. In the rural areas of most developing countries where the availability of piped water is limited and in most cases non-existent, the communities utilise stream/river water for drinking and other domestic uses. Indirect exposure routes include consumption of filter feeders such as molluscs which concentrate pathogenic microorganisms occurring in contaminated water (Tamburrini and Pozio 1999). In the face of climatic change and increasing water scarcity, wastewater is increasingly being considered as a new source of water for irrigation in regions where water is scarce (Blumenthal et al. 2000), exposing farmers to the risk of infection with vibrios and other waterborne pathogens. Issues of public health, as related to both water quantity and quality, are, therefore, increasingly becoming of concern.

\section{Conclusion}

We conclude, therefore, that potentially virulent and multidrug resistant vibrios can be found in wastewater effluents of "healthy" communities. Even though $V$. cholerae was not assessed for in this work, we have reasonable suspicion, basing on the outcome of this work, that it is also prevalent in wastewater effluents owing to the existence of sub-clinical cholera cases in communities. The prevalence of vibrios in the aquatic milieu constitutes a public health risk to people living in underdeveloped regions with no access to potable water. The use of surface water contaminated with wastewater effluents for either irrigation or recreational activities can likely pose risk of infection from waterborne pathogens. We recommend that future studies of this kind be directed at screening and characterising $V$. cholerae since it is the major pathogenic species under the genus Vibrio and more so since $31.8 \%$ of the Vibrio isolates in this study fell outside the bracket of targeted Vibrio species.

Acknowledgments We wish to acknowledge the Water Research Commission (WRC) of South Africa for funding this research.

Open Access This article is distributed under the terms of the Creative Commons Attribution License which permits any use, distribution, and reproduction in any medium, provided the original author(s) and the source are credited.

\section{References}

Abbott SL, Janda JM (1994) Severe gastroenteritis associated with Vibrio hollisae infection: report of 2 cases and review. Clin Infect Dis 18: 310-312

Ahmadi A, Riahi H, Noori M (2005) Studies of the effects of environmental factors on the seasonal change of phytoplankton population in municipal waste water stabilization ponds. Toxicol Environ Chem $87: 543-550$

Arceivala SJ (1997) Sustainable wastewater treatment. AIC Watson Consultants Ltd., Mumbai

Asano T, Levine AD (1998) Wastewater reclamation, recycling, and reuse: an introduction. In: Asano $\mathrm{T}$ (ed) Wastewater reclamation and reuse. Technomic Publishing Company, Lancaster, pp 1-56

Atieno NR, Owuor OP, Omwoyo O (2013) Isolation of high antibiotic resistant fecal bacteria indicators, salmonella and vibrio species from raw abattoirs sewage in peri-urban locations of Nairobi, Kenya. Greener J Biol Sci 3(5):172-178

Baine WB, Farmer JJ, Gangerosa EJ, Hermann GT, Thornsberry C, Rice PA (1977) Typhoid fever in the United States associated with the 1972-73 epidemic in Mexico. J Infect Dis 135:649-653

BLACKSASH (2010) Eastern Cape Provincial Health Consultative workshop: a community consultation workshop report 10-12 May 2010. Port Elizabeth, Eastern Cape Province. http://www.blacksash. 
org.za/files/ec_consultworkshp_10052010.pdf. Accessed on 26 June 2014

Blumenthal UJ, Mara DD, Peasey A, Ruiz-Palacios G, Stott R (2000) Guidelines for the microbiological quality of treated wastewater used in agriculture: recommendations for revising who guidelines. Bull World Health Organ 78(9):1104-1116

Bourne DE, Coetzee N (1996) An atlas of potentially water-related diseases in South Africa. WRC Report No 584/1/96, Pretoria, South Africa.

Byarugaba DK (2004) A view on antimicrobial resistance in developing countries and responsible risk factors. Int J Antimicrob Agents 24: $105-110$

Carnahan A, Harding MJ, Watsky D, Hansman S (1994) Identification of Vibrio hollisae associated with severe gastroenteritis after consumption of raw oysters. J Clin Microbiol 32:1805-1806

CDC (Centers for Disease Control and Prevention) (1999) Outbreak of Vibrio parahaemolyticus infection associated with eating raw oysters and clams harvested from Long Island SoundConnecticut, New Jersey, and New York, 1998. Morb Mortal Wkly Rep 48:48-51

Centers for Disease Control and Prevention (2013) Cholera. Available at http://www.cdc.gov/cholera/index.html. Accessed 4 August, 2014.

Chakraborty R, Sinha S, Mukhopadhyay AK, Asakura M, Yamasaki S, Bhattacharya SK, Nair G, Ramamurthy T (2006) Species-specific identification of Vibrio fluvialis by PCR targeted to the conserved transcriptional activation and variable membrane tether regions of the toxR gene. J Med Microbiol 55:805-808

Chindah AC, Braide SA, Amakiri J, Izundu E (2007) Succession of phytoplankton in a municipal waste water treatment system under sunlight. Rev UDO Agríc 7:258-273

Crowther-Gibson P, Govender N, Lewis DA, Bamford C, Brink A, von Gottberg A, Klugman K, du Plessis M, Fali A, Harris B, Keddy KH, Botha M (2011) Part IV. GARP: human infections and antibiotic resistance. SAM J 101(8):567-578. doi:10.7196/samj.5102

Dalsgaard A, Forslund A, Serichantalergs O, Sandvang D (2000) Distribution and content of class 1 integrons in different Vibrio cholerae O-serotype strains isolated in Thailand. Antimicrob Agents Chemother 44:1315-1321

de Souza Costa Sobrinho P, Destro MT, Franco BDGM, Landgraf M (2010) Correlation between environmental factors and prevalence of Vibrio parahaemolyticus in oysters harvested in the Southern coastal area of Sao Paulo State, Brazil. Appl Environ Microb 76(4):1290 1293

DePola A, Nordstrom JL, Bowers JC, Wells JC, Cook DW (2003) Seasonal variation in the abundance of total and pathogenic Vibrio parahaemolyticus in Alabama oysters. Appl Environ Microbiol 69: $1521-1526$

Drury B, Rosi-Marshall E, Kelly JJ (2013) Wastewater treatment effluent reduces the abundance and diversity of benthic bacterial communities in urban and suburban rivers. Appl Environ Microbiol 79(6): $1897-1905$

ECSECC (2011) District demographic and socio-economic indicators: census $1996 ; 2001 ; 2011$. http://www.ecsecc.org/files/library/ documents/ECSECC Census.pdf. Accessed 01 June 2014

Faruque SM, Islam MJ, Ahmad QS et al (2005) Self-limiting nature of seasonal cholera epidemics: role of host-mediated amplifi cation of phage. Proc Natl Acad Sci U S A 102:6119-24

Finkelstein R, Edelstein S, Mahamid G (2002) Fulminant wound infections due to Vibrio vulnificus. Isr Med Assoc J 4:654-655

Gerritsen J, Smidt H, Rijkers GT, de Vos WM (2011) Intestinal microbiota in human health and disease: the impact of probiotics. Genes Nutr 6:209-240. doi:10.1007/s12263-011-0229-7

Gilbert DN, Moellering RC, Sande MA (1999) Sanford guide to antimicrobial therapy, 29th edn. Antimicrobial Therapy, Inc., Hyde Park

Harris JB, LaRocque RC, Qadri F, Ryan ET, Calderwood SB (2012) Seminar: cholera. Lancet 379:2466-76
Heidelberg JF, Heidelberg KB, Colwell RR (2002) Bacteria of the gamma-subclass proteobacteria associated with zooplankton in chesapeake Bay. Appl Environ Microbiol 68:5498-5507

Heymann D (2008) Vibrio choleraeserogroups 01 and 0139. In: Control of communicable diseases manual. 19th ed. Washington, DC: Am Pub Health Ass 120-128

Farmer JJ (III), Hickman-Brenner FW (1992) The genera Vibrio and Photobacterium, p. 2952-3011. In Balows A, Trüper HG, Dworkin M, Harder W, Schleifer KH (ed.). The prokaryotes. A handbook on the biology of bacteria: ecophysiology, isolation, identification, and applications, 2nd ed. Springer-Verlag KG, Berlin, Germany

Hlady WG (1997) Vibrio infections associated with raw oyster consumption in Florida, 1981-1994. J Food Protect 60:353-357

Igbinosa EO, Okoh AI (2010) Vibrio fluvialis: an unusual enteric pathogen of increasing public health concern. Int J Environ Res Public Health 7:3628-3643

Igbinosa EO, Obi CL, Okoh AI (2009) Occurrence of potentially pathogenic vibrios in the final effluents of a wastewater treatment facility in a rural community of the Eastern Cape Province of South Africa. Res Microbiol 160:531-537

Igbinosa EO, Obi CL, Okoh AI (2011) Seasonal abundance and distribution of Vibrio species in the treated effluents of wastewater treatment facilities in suburban and urban communities of Eastern Cape Province, South Africa. J Microbiol 49(2):224-232

Illinois Department of Natural Resources (2011) Illinois Coastal Management Program issue paper: Chicago River and North Shore Channel corridors. Illinois Department of Natural Resources. Springfield, IL

Iwamoto M, Ayers T, Mahon BE, Swerdlow DL (2010) Epidemiology of seafood-associated infections in the United States. Clin Microbiol Rev 23(2):399-411. doi:10.1128/CMR.00059-09

Jackson S. Beney C (2000) Detection of Vibrio cholerae in river water in the vicinity of an informal settlement. Presented at the WISA 2000 Biennial Conference, Sun City, South Africa, 28 May - 1 June 2000. http://www.ewisa.co.za/literature/files/237jackson.pdf. Accessed on 26 June 2014

James AE, Ian P, Helen S, Sojka RE (2003) Polyacrylamide $+\mathrm{Al}_{2}\left(\mathrm{SO}_{4}\right)_{3}$ and polyacrylamide $+\mathrm{CaO}$ remove coliform bacteria and nutrients from swine wastewater. Environ Res 121:453-462

Janda JM, Powers C, Bryant RG, Abbott S (1988) Current perspectives on the epidemiology and pathogenesis of clinically significant Vibrio spp. Clin Microbiol Rev 1:245-267

Jiménez B, Barrios J, Mendez J, Diaz J (2004) Sustainable management of sludge in developing countries. Water Sci Technol 49(10):251-8

Keddy K (2010a) Cholera outbreak in South Africa: extended laboratory characterisation of isolates. In: National Health Laboratory Service - annual report 2009/2010. Sandringham, GA: National Health Laboratory Service.

Keddy K (2010b) Molecular characterisation of multidrug resistant cholera outbreak isolates. In: National Health Laboratory Serviceannual report 2009/2010. Sandringham, GA: National Health Laboratory Service.

Kim YB, Okuda J, Matsumoto C, Takahashi N, Hashimoto S, Nishibichi M (1999) Identification of Vibrio parahaemolyticus strains at the species level by PCR targeted to the toxR gene. J Clin Microbiol 37:1173-1177

Kobayashi K, Ohnaka T (1989) Food poisoning due to newly recognized pathogens. Asian Med J 32:1-12

Kothary MH, Lowman H, Mccardell BA, Tall BD (2003) Purification and characterization of enterotoxigenic El Tor-like hemolysin produced by Vibrio fluvialis. Infect Immun 71:3213-20

Kwok AY, Wilson JT, Coulthart M, Ng LK, Mutharia L, Chow AW (2002) Phylogenetic study and identification of human pathogenic Vibrio species based on partial hsp60 gene sequences. Can J Micriobiol 48:903-910 
Levine WC, Griffin PM (1993) Vibrio infections on the Gulf Coast: results of first year of regional surveillance Gulf Coast Vibrio Working Group. J Infect Dis 167:479-483

Mackintosh G, Colvin C (2003) Failure of rural schemes in South Africa to provide potable water. Environ Geol 44:101-105

Maugeri TL, Carbone M, Fera MT, Gugliandolo C (2006) Detection and differentiation of Vibrio vulnificus in seawater and plankton of coastal zone of the Mediterranean Sea. Res Microbiol 157:194-200

Mishra M, Mohammed F, Akulwar SL, Katkar VJ, Tankhiwale NS, Powar RM (2004) Re-emergence of El Tor Vibrio in outbreak of cholera in and around Nagpur. Indian J Med Res 120:478-480

Mohale NG (2003) Evaluation of the adequacy and efficiency of sewage treatment works in Eastern Cape. Rhodes University, South Africa, MSc. Thesis

Mukhopadhyay SK, Chattopadhyay B, Goswami AR, Chatterjee A (2007) Spatial variations in zooplankton diversity in waters contaminated with composite effluents. J Limnol 66:97-106

Nair L, Sudarsana J, Pushpa KK (2004) Epidemic of Salmonella enteritica serotype paratyphi a in Calicut-Kerala. Calicut Med J 2:e2

Nelson EJ, Chowdhury A, Flynn J et al (2008) Transmission of Vibrio cholerae is antagonized by lytic phage and entry into the aquatic environment. PLoS Pathog 4:e1000187

Nevondo TS, Cloete TE (2001) The global cholera pandemic. http:// www.scienceinafrica.com/old/index.php?q=2001/september/ cholera.htm. Accessed 04 June 2014

New York Times (2013) http://www.nytimes.com/2013/09/17/health/ cdc-report-finds-23000-deaths-a-year-from-antibiotic-resistantinfections.html. Accessed 21 April 2014

Obi CL, Bessong PO, Momba MNB, Potegieter N, Samie A, Igumbor EO (2004) Profile of antibiotic susceptibilities of bacterial isolates and physicochemical quality of water supply in rural Venda communities of South Africa. Water SA 30:515520

Okoh AI, Igbinosa EO (2010) Antibiotic susceptibility profiles of some Vibrio strains isolated from wastewater final effluents in a rural community of the Eastern Cape Province of South Africa. BMC Microbiol 10:143. doi:10.1186/1471-2180-10-143

Oliver JD, Kaper JB (2001) Vibrio species. In food microbiology $2^{\text {nd }}$ edn (Doyle MP, Beuchat LR, Movtville TJ (Eds), pp 228-264 ASM Press, Washington. DC, USA

Osorio CR, Klose KE (2000) A region of the transmembrane regulatory protein Tox $R$ that tethers the transcriptional activation domain to the cytoplasmic membrane displays wide divergence among Vibrio species. J Bacteriol 182:526-528
Pegram GC, Rollins N, Espey Q (1998) Estimating the cost of diarrhea and epidemic dysentery in KwaZulu-Natal and South Africa. Water SA 24(1):11-20

Sayah RS, Kaneene JB, Johnson Y, Miller RA (2005) Patterns of antimicrobial resistance observed in Escherichia coli isolates obtained from domestic- and wild-animal fecal samples, human septage, and surface water. Appl Environ Microbiol 71:13941404

Standard Methods (2005) Standard methods for the examination of water and wastewater. 20th Edn. American Public Health Association (APHA): Washington DC, USA.

Steinberg EB, Greene KD, Bopp CA, Cameron DN, Wells JG, Mintz ED (2001) Cholera in the United States, 1995-2000: trends at the end of the twentieth century. J Infect Dis 184(6):799-802

Tamburrini A, Pozio E (1999) Long-term survival of Cryptosporidium parvum oocysts in seawater and in experimentally infected mussels (Mytilus galloprovincialis). Int J Parasitol 29:711-715

Tarr CL, Patel JS, Puhr ND, Sowers EG, Bopp CA, Strockbine NA (2007) Identification of Vibrio isolates by a multiples PCR assay and $r p o B$ sequence determination. J Clin Microbiol 45(1):134-140

Tendencia EA, De la Pena LD (2002) Level and percentage recovery of resistance to oxytetracycline and oxolinic acid of bacteria from shrimp ponds. Aquaculture 213:1-13

Todar K (2005) http://textbookofbacteriology.net/cholera.html Accessed 06 June 2014.

Torrice M (Undated) Multidrug resistance gene released by Chinese wastewater treatment plants. http://science-beta.slashdot.org/story/ 13/12/18/0013200/multidrug-resistance-gene-released-by-chinesewastewater-treatment-plants. Accessed on 08 April 2014

Van den Bogaard AE, Stobberingh EE (2000) Epidemiology of resistance to antibiotics - links between animals and humans. Int J Antimicrob Agents 14:327-335

WASH (2010) News about water, sanitation and hygiene (WASH) in Africa. URL: http://washafrica.wordpress.com/2010/07/16/southafrica-shortage-of-fresh-water-supplies-looming/. Accessed on 30 April 2014

Wen Q, Tutuka C, Keegan A, Jin B (2009) Fate of pathogenic microorganisms and indicators in secondary activated sludge wastewater treatment plants. J Environ Manag 90:1442-1447

Wenzel RP, Edmond MB (2009) Managing antibiotic resistance. J Med 343:1961-1963

Wong RS, Chow AW (2002) Identification of enteric pathogens by heat shock protein $60 \mathrm{kDa}$ (HSP60) gene sequesnces. FEMS Microbiol Lett 206:107-113 